\title{
Sistem Informasi Persediaan Obat Berbasis Web Pada Puskesmas Kotabumi Tangerang
}

\author{
Brian Kevin Imora ${ }^{1}$, Rahmat Hidayat ${ }^{2}$, Yusnia Budiarti ${ }^{3}$ \\ 1,3 STIMK Nusa Mandiri

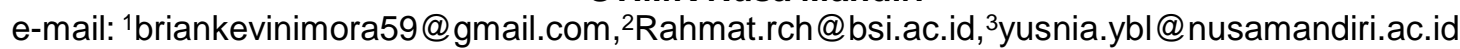

\begin{abstract}
Abstrak
Puskesmas Kotabumi Tangerang, merupakan salah satu pusat pelayanan kesehatan masyarakat yang berada pada Kecamatan Kota bumi Tangerang, pada puskesmas tersebut sistem pengolahan data masih dilakukan secara manual yaitu menulis atau mencatat stok di buku sehingga banyak ditemukan kendala yang menyebabkan proses kerja tidak efektif dan efesien, diantaranya kesalahan dalam pencatatan data obat yang masuk maupun keluar hal ini mengakibatkan persediaan obat menjadi kosong atau berlebih.Tujuan Penilitian ini untuk merancang satu sistem informasi persediaan obat yang lebih efektif dan efisien untuk dapat dipergunakan pada Puskesmas Kotabumi Tangerang, metode pengumpulan data yang digunakan yaitu observasi, wawancara, studi kepustakaan, bahasa pemrograman PHP, MySQL database yang dijalankan pada Xampp, dengan adanya penelitian ini di harapkan dapat membantu apoteker dalam mengelola data transaksi dan stok obat secara efisien yang ada pada puskesmas Kotabumi Tangerang.
\end{abstract}

Kata kunci: Informasi, Persediaan, MySQL, PHP, Obat, Sistem, Website

\begin{abstract}
Puskesmas Kotabumi Tangerang, is one of the community health service centers located in Kotabumi Tangerang District, at this puskesmas the data processing system is still done manually, namely writing or recording stock in books so that many obstacles are found that cause the work process to be ineffective and efficient, including errors In recording incoming and outgoing drug data this results in an empty or excessive supply of drugs. The purpose of this study is to design a drug supply information system that is more effective and efficient to be used at the Kotabumi Public Health Center in Tangerang, the data collection methods used are observation, interviews, literature study, PHP programming language, MySQL database which is run on Xampp, this research is expected to help pharmacists in managing transaction data and drug stocks efficiently available at Kotabumi Public Health Center, Tangerang.
\end{abstract}

Keywords:Information, Inventory, MySQL, PHP, Medicines,Systems, Websites

\section{Pendahuluan}

Perkembangan ilmu teknologi dan peran teknologi dalam perkembangan dibidang kesehatan sangat pesat dan maju. Hal tersebut dapat dilihat dari penerapan dan pemanfaatan teknologi hanpir disemua bidang terutama di bidang kesehatan baik unit kesehatan di tingkat masyarakat, pemerintah maupun swasta. Saat ini peran komputer sebagai teknologi yang dapat digunakan untuk pengolah data dan dapat menghasilkan sebuah informasi yang digunakan untuk mendukung segala aktifitas kegiatan sehari hari manusia. Tingginya tingkat kesalahan dalam pemprosesan dan pembuatan laporan di banyak perusahaan yang memanfaatkan teknologi informasi terutama di bidang kesehatan dalam hal ini puskesmas sebagai pusat kesehatan masyarakat yang hampir disetiap kecamatan diseluruh Indonesia berada, menjadi pendorong psukesmas untuk memperbaiki sistem pengolahan datanya, sehingga informasi yang dihasilkan dapat digunakan dalam proses pengambilan keputusan dan dapat juga digunakan untuk mengontrol kegiatan operasional.

Puskesmas merupakan bentuk unit pelayanan kesehatan masayarakat dimana terdapat unit apotek, merupakan salah satu bentuk unit bagian yang sangat penting dan yang sangat membutuhkan dukungan 
teknologi informasi guna mendukung aktivitas kegiatan yang dijalankannya. Salah satu proses inti dalam unit apotek, yaitu dalam mengelola persediaan obat dengan jumlah besar dan spesifikasi yang berbeda-beda.

Puskesmas Kotabumi Tangerang memiliki salah satu unit apotek yang pengolahan data persediaan obatobatannya masih menggunakan sistem konvensional, dimana kegiatan pengelolaan persediaan masih dilakukan secara manual, tanpa bantuan komputer. Proses pencatatan data laporan obat dengan menggunakan dua macam buku pencatatan yaitu buku pemesanan obat harian, buku rekap penjualan obat harian, dan tiga macam kartu pencatatan stok yaitu kartu daftar detail obat masuk dari Gudang Farmasi, kartu stok per item, kartu rekap stok. Dan setiap bukti penerimaan obat dari Gudang Farmasi Dinkes Tangerang selalu disimpan sebagai cadangan jika dari kedua buku dan ketiga kartu pencatatan ada yang terlewat.

Dengan menggunakan sistem manual ini banyak ditemukan kendala yang menyebabkan proses kerja tidak efektif dan efesien, diantaranya kesalahan dalam pencatatan data obat yang masuk maupun keluar sehingga mengakibatkan persediaan obat menjadi kosong atau berlebih, dan ditemukannya obat kadaluarsa. Dalam mengelola data obat memang sangat dibutuhkan ketelitian, baik untuk pencatatan stok akhir maupun manejemen obat masuk dari Gudang Farmasi Dinkes Tangerang.

Selain itu juga masih sering ditemukan ada beberapa data pengeluaran dan penerimaan yang terlewat untuk dicatat, termasuk beberapa aktivitas lain diantaranya adalah pengarsipan, pembuatan rekap, jadwal pemesanan dan penerimaan, serta ketersediaan jumlah stok obat antara yang di catat dengan fisik tidak sesuai.

Pada penelitian yang dilakukan oleh Ria Wenny Asriani yang berjudul "Analisis Dan Perancangan Sistem Informasi Persediaan Obat (Studi Kasus Puskesmas Kecamatan Rimbo Bujang)" Penelitian yang dilakukan Ria Wenny Asriani ini cukup relevan dengan penelitian skripsi ini, dimana objek yang diteliti yaitu Puskesmas kecamatan Rimbo Bujang masih menggunakan sistem manual dalam pencatatan persediaan obat dan belum menggunakan database sama halnya dengan Puskesmas Kotabumi Tangerang. Pada penelitian ini juga memiliki persamaan yaitu merancang sebuah sistem persediaan obat yang dapat melakukan perhitungan persediaan obat secara otomatis sehingga meminimalisir kesalahan dan mempercepat pembuatan laporan pemakaian dan lembar permintaan obat untuk perbulan maupun pertiga bulan. Perbedaannya pada penelitian yang dilakukan Ria Wenny Asriani ini membahas tentang pembelian obat, sedangkan pada Puskesmas Kotabumi Tangerang tidak ada proses pembelian obat dikarenakan obat diberikan gratis oleh pemerintah berupa obat generik yang di ambil setiap bulan atau pertiga bulan ke Gudang Farmasi Kabupaten Tangerang [1].

Berdasarkan paparan di atas, sebagai solusi dari permasalahanpermasalahan yang saat ini dialami oleh Puskesmas Kotabumi Tangerang tersebut, penulis tertarik untuk melakukan penelitian guna membangun suatu sistem informasi persediaan obat di Puskesmas Kotabumi Tangerang. Dengan tujuan agar pengelolaan persediaan obat lebih akurat, teratur dan mempermudah dalam melakukan pencarian data stok obat, sekaligus secara tidak langsung dapat meningkatkan kinerja serta efektifitas kerja di Puskesmas Kotabumi Tangerang.

\section{Metode Penelitian}

2.1. Pada bagian bab ini dipaparkan beberapa teori-teori serta dari sumber pustaka sebagai landasan penulisan skripsi ini. Adapun untuk teori-teori ini diambil dari anatra lain buku literatur dan ada yang dari internet. Teori yang dibahas meliputi teori tentang konsep Unified Modeling Language (UML)

Menurut Shalahuddin (2015:137) “ UML merupakan bahasa visual untuk permodelan dan komunikasi mengenai sebuah sistem dengan menggunakan diagram dan teks-teks pendukung".

Menurut Shalahuddin (2015:140) “

Secara fisik, UML adalah sekumpulan spesifikasi yang dikeluarkan oleh OMG ( Object Management Group )". UML terbaru adalah UML 2.3 yang terdiri dari 4 macam spesifikasi yaitu diagram interchange Specification, UML Infrastructure, UML Superstructure, dan Object Constraint Languange (OCL). Seluruh spesifikasi dapat diakses di website 
http://www.omg.org. Berikut beberapa jenis diagram:

1. Diagram Use Case (Use-Case-
Diagram)

Menurut Shalahuddin (2015:155) "Use case

merupakan permodelan untuk melakukan (behavior) sistem informasi yang akan dibuat". Use case mendeskripsikan sebuah interaksi antara satu atau lebih actor dengan sistem informasi yang akan dibuat. Ada dua hal utama pendefinisian pada use case yaitu aktor dan use case.

a. Aktor merupakan orang, proses atau sistem lain yang berinteraksi dengan sistem lain yang berinteraksi dengan sistem informasi yang akan dibuat di luar sistem informasi yang akan di buat itu sendiri, jadi walaupun simbol dari aktor adalah gambar orang, tapi aktor belum tentu merupakan orang. Menggambarkan pihak-pihak yang berperan dalam sistem.

b. Use Case merupakan fungsionalitas yang di sediakan sistem sebagai unit-unit yang saling bertukar pesan antar unit atau aktor.

\section{Diagram aktivitas (Activity Diagram)}

Menurut Shalahuddin (2015:161) "Activity diagram menggambarkan workflow (aliran kerja) atau aktivitas dari sebuah sistem atau proses bisnis atau menu yang ada pada perangkat lunak". Diagram aktivitas menggambarkan aktivitas sistem bukan apa yang dilakukan aktor jadi aktivitas yang dapat dilakukan oleh sistem.

\section{Diagram Interaksi (Sequence Diagram)}

Menurut Shalahuddin (2015:165) "Diagram sekuen menggambarkan kelakuan objek pada use case dengan mendeskripsikan waktu hidup objek dan message yang dikirimkan dan diterima antar objek". Oleh karena itu untuk menggambar diagram sekuen maka harus di ketahui objek-objek yang terlibat dalam sebuah use case beserta metode-metode yang dimiliki kelas yang yang di instansiasi menjadi objek itu.

\section{$4 . \quad$ Diagram} (Deployment Diagram )

Menurut Shalahuddin (2015:154) "Deployment diagram menujukkan konfigurasi komponen dalam proses eksekusi aplikasi". Diagram deploymen juga dapat digunakan untuk memodelkan hal-hal berikut :
a) Sistem
system)
tambahan (embended
yang menggambarkan

rancangan device, node, dan hardware.

b) Sistem client atau server dan hardware.

c) Sistem terdistribusi murni.

d) Rekayasa ulang aplikasi.

\subsection{Penelitian Terkait}

Berikut ini beberapa penelitianpenelitian terkait yang menjadi referensi penulisan skripsi ini :

Hanik Mujiati, "Analisis dan Perancangan Sistem Informasi Stok Obat Pada Apotek Arjowinangun",2016.

Penelitian yang dilakukan Hanik Mujiati bertujuan menghasilkan perancangan sistem informasi stok obat. Ruang lingkup permasalahan penelitian yang dilakukan adalah bagaimana membangun sistem informasi stok obat pada Apotek Arjowinangun. Tujuan dari penelitian ini adalah untuk menghasilkan perancangan sistem informasi stok obat pada Apotek Arjowinangun.

Dan penelitian yang dilakukan oleh:

Ria Wenny Asriani, "Analisis Dan Perancangan Sistem Informasi Persediaan Obat (Studi Kasus Puskesmas Kecamatan Rimbo Bujang)", 2015.

Penelitian yang dilakukan Ria Wenny Asriani ini cukup relevan dengan penelitian skripsi ini, dimana objek yang diteliti yaitu Puskesmas kecamatan Rimbo Bujang masih menggunakan sistem manual dalam pencatatan persediaan obat dan belum menggunakan database sama halnya dengan Puskesmas Kutabumi Tangerang. Pada penelitian ini juga memiliki persamaan yaitu merancang sebuah sistem persediaan obat yang dapat melakukan perhitungan persediaan obat secara otomatis sehingga meminimalisir kesalahan dan mempercepat pembuatan laporan pemakaian dan lembar permintaan obat untuk perbulan maupun pertiga bulan. Perbedaannya pada penelitian yang dilakukan Ria Wenny Asriani ini membahas tentang pembelian obat, sedangkan pada Puskesmas Kutabumi Tangerang tidak ada proses pembelian obat dikarenakan obat diberikan gratis oleh pemerintah berupa obat generik yang di ambil setiap bulan atau pertiga bulan ke Gudang Farmasi Kabupaten Tangerang. 


\section{Tinjauan Perusahaan}

Puskesmas Kutabumi berlokasi di Perumahan Pondok Indah Kutabumi, Jalan Cana Raya Rt 03/07 Kelurahan Kutabumi Kecamatan Pasar Kemis, sebagai puskesmas induk Kecamatan Pasar Kemis dengan luas tanah 2000 M2 dan luas bangunan kurang lebih $1750 \mathrm{M} 2$.

$$
\text { Jarak Puskesmas Kutabumi }
$$

dengan Pusat Pemerintahan Kabupaten dalam hal ini Dinas Kesehatan Kabupaten Tangerang yaitu kurang lebih $30 \mathrm{~km}$ sedangkan jarak dengan dengan pemerintahan Kecamatan Pasar Kemis kurang lebih $5 \mathrm{~km}$.

\subsection{Proses Bisnis}

Berikut ini adalah prosedur sistem yang sedang berjalan dibagian farmasi/apotik UPT Puskesmas Kutabumi:

Dari Gudang obat petugas mencatat persediaan obat yang ada di gudang obat secara manual terlebih dahulu, selanjutnya petugas gudang mengeluarkan obat dan data obat ke apotek, lalu petugas apotek mengelola data obat masuk menggunakan excel, setelah selesai, data disimpan dan dicetak untuk diarsipkan, lalu melaporkaan data obat kepada dinas kesehatan dimana sudah ditanda tangan dan memberikan kembali ke Apotek laporan yang telah ditanda tangan sebagai lampiran.

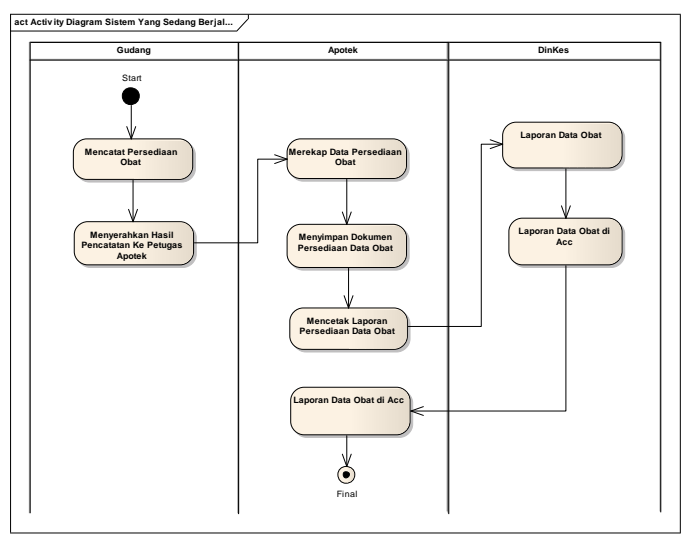

Gambar 3.1 Activity Diagram Sistem Yang Sedang Berjalan

\section{Analisa Kebutuhan Software}

4.1 Tahapan Analisis

Sistem inventory secara online berbasis web adalah sebuah layanan yang disediakan managemen perusahaan untuk mempermudah proses pengontrolan stok obat dan keluar masuknya obat, dimana setiap transaksi pengeluaran obat dan pemesanan tidak lagi dilakukan dengan pencatatan manual. Selain itu, sistem inventory berbasis web ini juga berfungsi sebagai penghubung antara pihak manajemen dan karyawan dalam berbagai proses lain yang terkait

\section{a. Usecase diagram}

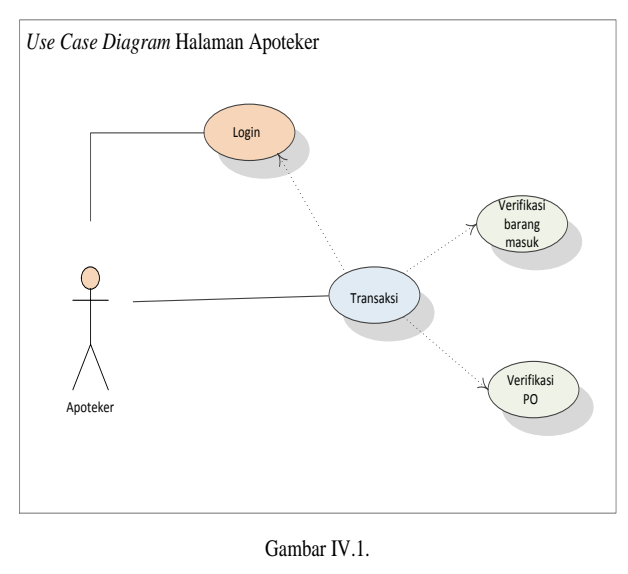

Use Case Diagram Halaman Apoteker

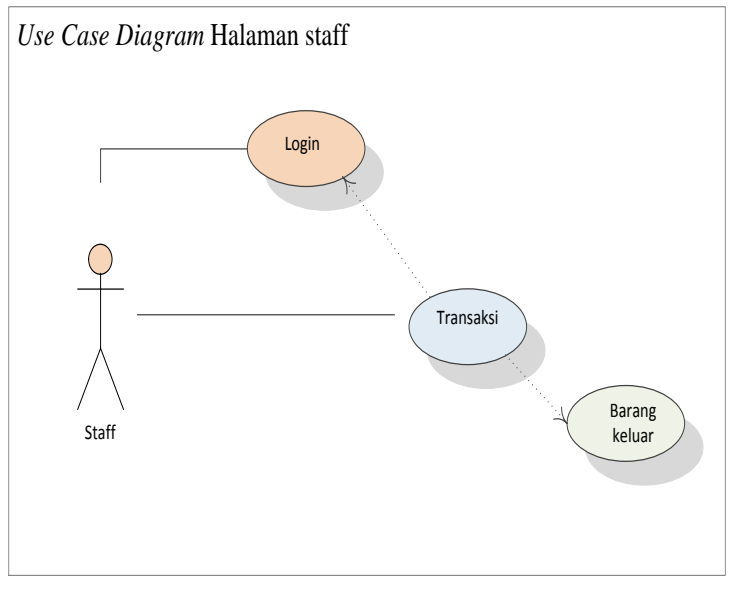

Gambar IV.2.

Use Case Diagram Halaman Staff

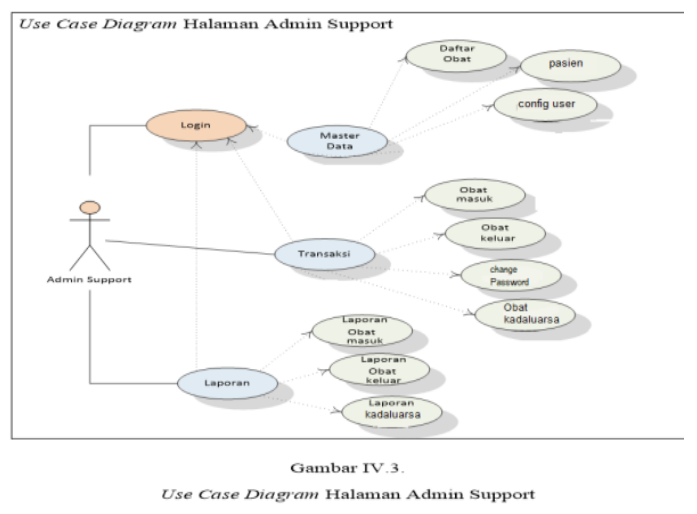


b. Entity Relationship Diagram

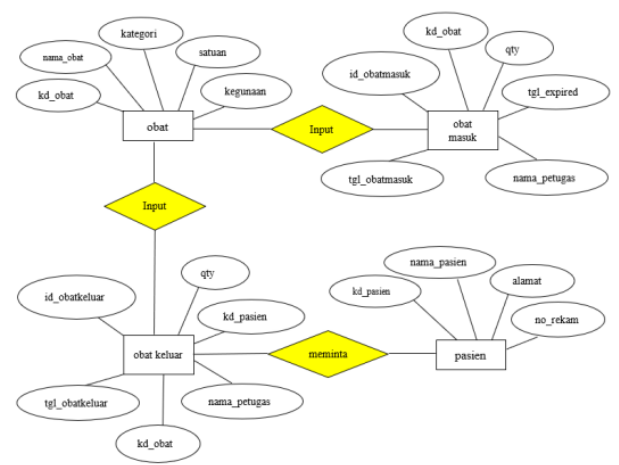

Gambar 4.4.

Entity Relationship Diagram

a. User Interface

1. Halaman Login

Gambar 4.5.

Tampilan Login

2

Halaman Admin

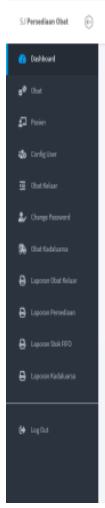

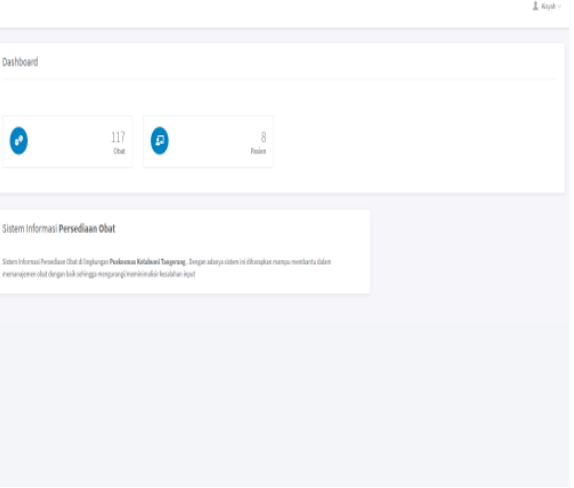

Gambar 4.6.

Tampilan Halaman Admin

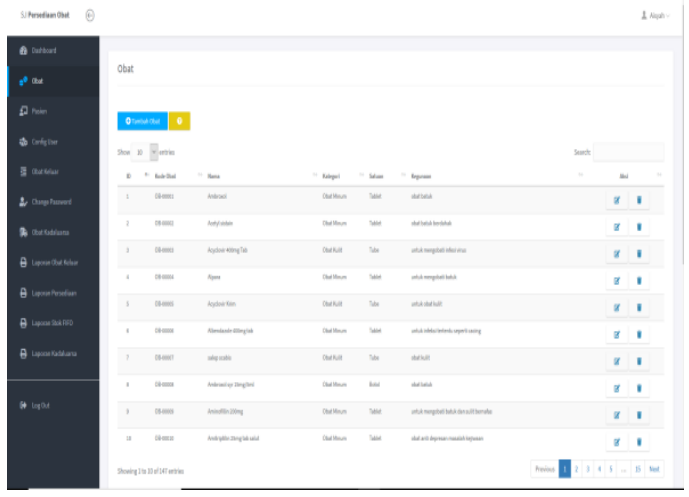

Gambar 4.7.

Tampilan Master Data Daftar Obat

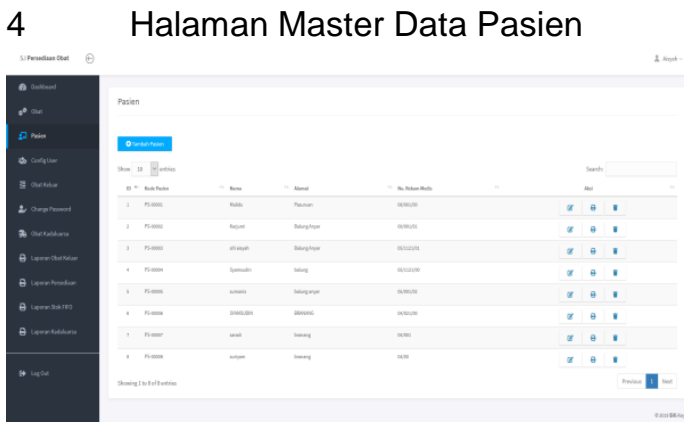

Gambar 4.8.

Tampilan Master Data Pasien

\section{Penutup}

\subsection{Kesimpulan}

Setelah membuat sistem informasi persediaan obat berbasis web pada Puskesmas Kotabumi Tangerang ini diharapkan dapat mempermudah sistem persediaan serta pembuatan laporan obat yang akurat dan efisien, maka penulis dapat memberikan beberapa kesimpulan, diantaranya yaitu :

1. Sistem persediaan ini diharapkan dapat membantu mempermudah pencatatan yang terkomputerisasi sehingga dapat meningkatkan pelayanan dan pengawasan obat Puskesmas Kotabumi Tangerang.

2. Pengolahan data obat nantinya dapat dilakukan secara cepat, tepat dan akurat serta terhindar dari kesalahan pemasukan data.

3. Sistem komputerisasi dapat digunakan sebagai hasil dari pengembangan teknologi yang membantu dalam menangani proses pengolahan data transaksi sehingga dapat memudahkan 
dalam pengawasan keluar masuk obat yang lebih baik.

4. Pencarian data yang dapat lebih cepat dan mudah karena semua data obat sudah memiliki database.

5. Penerapan sistem informasi persediaan obat ini akan mempermudah kegiatan operasional apotek serta dapat meningkatkan kinerja yang efektif dan efisien.

\subsection{Saran}

Berdasarkan kesimpulan dari pembahasan dan penjelasan diatas, penulis memberikan saran-saran yang dapat dijadikan masukan yang sangat berguna dan bermanfaat bagi Puskesmas Kotabumi Tangerang, yaitu sebagai berikut:

1. Agar penggunaan sistem informasi persediaan ini dapat berjalan dengan baik maka perlu diadakannya pelatihan terrhadap user agar penggunaan program apliksi informasi ini dapat berfungsi optimal.

2. Bagi pemilik atau pengelola web ini agar meng-update obat secara berkala agar staf penjualan bisa melihat informasi produk dengan detail.

3. Bagi pengelola web harus melakukan maintenance agar meminimalisir terjadinya masalah didalam web.

4. Bagi pengelola web harus secara berkala melakukan back up untuk mengantisipasi terjadinya kejahatan dengan hilang atau error nya sebuah website.

\section{Referensi}

R. W. Asriani, Analisis Dan Perancangan Sistem Informasi Persediaan Obat (Studi Kasus : Puskesmas Kecamatan Rimbo Bujang), Jambi: Stikom Dinamika Bangsa Jambi, 2015.

T. Sutabri, Analisis Sistem Informasi, Yogyakarta: Andi, 2012.

H. Mujiati, Analisis dan Perancangan Sistem Informasi Stok Obat pada Apotek Arjowinangun, J. Indonesian. J. Comput. Sci. Speed FTI UNSA, 2015.

d. S. Minarni, Sistem Informasi Inventory Obat pada Rumah Sakit Umum Daerah Padang, Padang: Volume 16, No.1, 2014.

P. P. Widodo, Menggunakan UML, Bandung: Informatika, 2011.

D. Sutaji, Sistem Inventory Mini Market dengan PHP \& JQUERY, Yogyakarta: Lokomedia, 2012.

M. Sukarno, Definisi Website, Bandung: Alfabeta., 2006.

Rizky, Konsep Dasar Rekayasa Perangkat Lunak, Jakarta: Prestasi Pustaka, 2011.

A. Nugroho, Rekayasa Perangkat Lunak Menggunakan UML \& Java, Yogyakarta : Andi Offset, 2010.

E. d. J. M. Irwansyah, Pengantar Teknoogi Informasi, Yogyakarta: Depublish, 2014. 
